ISSN $1676-3742$

\title{
Trindade e apofatismo no pensamento de Gregório de Nissa
}

\author{
Trinity and apophatism in the thought \\ of Gregory of Nyssa
}

Maria Freire da Silva

\section{Resumo}

O objetivo desse artigo "Trindade e apofatismo em Gregório de Nissa" é estudar, pondo em relevo o uso da linguagem apofática na compreensão de Deus como Revelatus e Absconditus em perspectiva trinitária. Ainda objetiva verificar quais as contribuições dessa linguagem para a linguagem trinitária no pensamento teológico atual. A influência desse teólogo e seu pensamento constituem a autêntica evolução do pensar teológico, permitindo a afirmação da Trindade Pessoal no Concílio de Constantinopla I (381) e mantendo fidelidade ao princípio de unidade confessado no Concílio de Nicéia I (325). Trata-se do desenvolvimento da doutrina cristã na qual a questão da divindade do Logos, a segunda pessoa do dogma trinitário, se apresenta prioritariamente.

Palavras-Chave: Comunhão; Trindade; apofatismo; Revelação.

\section{Abstract}

This article: the Trinity and apophatism in the thought of Gregory of Nyssa, looks into studying, stressing the use of the apophatic language in the understanding of God as Revelatus and Absconditus in the trinitarian perspective. It also aims at verifying the contributions of this language to the trinitarian language in the current theological thought. The influence of this 
theologian and his thoughts constitute the true evolution, allowing the assertion of the Personal Trinity at the Council of Constantinople I (381) and maintaining fidelity to the principle of unity confessed at the Council of Nicaea I (325). It ilustrates the development of the Christian doctrine in which the question of the divinity of the Logos, the second person of the Trinitarian dogma presents itself as a priority.

Keywords: Communion; Trinity; apophatism; revelation.

\section{Introdução}

A teologia trinitária ganha profunda relevância em Basílio o Grande, Gregório Nazianzeno e Gregório de Nissa pelo entendimento até então jamais experimentado na teologia. A influência desses teólogos e seu pensamento constituem a autêntica evolução, permitindo a afirmação da Trindade Pessoal no Concílio de Constantinopla I (381) e mantendo fidelidade ao princípio de unidade confessado no Concílio de Nicéia I (325). Trata-se do desenvolvimento da doutrina cristã na qual a questão da divindade do Logos, a segunda pessoa do dogma trinitário se apresenta prioritariamente.

Na busca incessante do estabelecimento de uma ortodoxia cristã, uma das discussões teológicas de maior relevo no cenário do século IV d.C. foi a que almejava dar uniformidade às interpretações cristológicas, ou seja, àquelas que discutiam a respeito da natureza de Jesus como Filho gerado do Deus Pai. A defesa da divindade do Espírito Santo não conseguiu impor-se a ponto de evitar interpretações subordinacionistas, até que não se compreendeu e se lhe deu lugar próprio em relação ao do Pai e ao Filho. A abordagem devida aos capadócios consistiu em afirmar o modo de ser de Deus do Espírito Santo no interior da Trindade, mantendo a distinção dentro da unidade, chegando à confissão da única substância em três Pessoas.

Destarte, é de suma importância a reflexão sobre a linguagem trinitária dos padres capadócios no século IV, particularmente de Basílio Magno e de Gregório de Nissa, sobre o conceito de pensamento humano que se faz necessário para defender a ortodoxia trinitária contra o neo-arianista Eunômio antes do Concílio de Constantinopla I (381). Isso aprofunda de modo original o resultado em que era comum a tradição Alexandrina e dava uma nova contribuição à discussão sobre a origem da linguagem a respeito do dogma trinitário. 


\section{Contexto biográfico de Gregório de Nissa}

Nascido em Cesaréia da Capadócia, é irmão de São Basílio, dois anos mais novo. Sua iniciadora na vida espiritual será sua irmã Macrina, que, depois da morte do pai, transformou todas as domiciliares de um dos seus domínios numa espécie de mosteiro doméstico. Gregório de Nissa está entre os três famosos capadócios, Basílio de Cesareia, seu irmão e Gregório Nazianzeno, ambos criadores da linguagem trinitária no século IV, considerados na Teologia como os luminares do Oriente. Nissa recebeu formação cultural e filosófica em uma escola retórica em Cesaréia da Capadócia, onde, entre suas leituras, recorre provavelmente a Platão, Aristóteles, aos escritos dos estóicos e também Plotino. Sua exegese espiritual segue a linha alexandrina de Filon.

Gregório de Nissa que só estudou na Capadócia, dominou, no entanto, a filosofia antiga, cujos conceitos transformarão radicalmente, tanto estóicos como platônicos, no crisol da revelação. Retórico, esposou Teosébia, mulher de grande cultura e grande fé, o que não o impediu de forma alguma de se tomar bispo de Nissa em 371, atendendo um pedido constrangedor de Basílio de Cesaréia que se prevenia contra o poder imperial, multiplicando, na sua metrópole, os bispados e entregando-os a homens de sua confiança ${ }^{1}$.

Homem de caráter meditativo, com grande capacidade de reflexão, de inteligência desperta, aberta, soube mergulhar na cultura de seu tempo ${ }^{2}$. Nissa é, dentre os capadócios, o menos estudado no passado; entretanto, no século $\mathrm{XX}$, o Nisseno passou a ser um dos padres da Igreja mais pesquisados ${ }^{3}$. Do ponto de vista de Papa a historiografia valoriza as ações de Gregório de Nissa. Somente a partir da década de 1990 é que percebemos, na bibliografia consultada até o momento, estudos que valorizam as ações do Bispo Gregório de Nissa enquanto autoridade atuante em seu espaço de negociação ${ }^{4}$.

Papa ainda afirma que ao abordar as notícias biográficas de Gregório de Nissa, Ronald E. Heine vincula as importantes atuações do Nisseno nas

\footnotetext{
${ }^{1}$ MORESCHINI. I padri cappadoci, storia, letteratuta, teologia. Roma: Città Nuova, 2008, p. 09.

2 BENEDITO XVI. Los padres de la Iglesia, De Clemente de Roma a san Agustin. Madrid: Ciudad Nueva, 2008, p. 119. Gregório deixou poucos escritos em níveis pessoais e íntimos. (PETERS, G. I padri dela chiesa, dal concilio di Nicea a Gregório Magno (+604). Roma: Borla, 1991, p. 121.

${ }^{3}$ PAPA, Helena, Amália. "O ideal político-religioso niceno na defesa da divindade de Jesus Cristo: considerações iniciais sobre a visão de Gregório de Nissa (séc. IV d.C.)”. In: Anais do XXVI Simpósio Nacional de História - ANPUH, São Paulo, julho 2011, p. 12.

${ }^{4}$ Idem, p. 13.
} 
reuniões eclesiásticas, bem como, sua inserção na corte e consequente relação com o Imperador Teodósio e os assuntos político-administrativo-religiosos de seu governo". Nissa "atuou decisivamente no Segundo Concílio Ecumênico em Constantinopla (381 d.C.) que assinalou o triunfo da ortodoxia trinitária. $\mathrm{Na}$ ocasião, seu nome figurou ao lado dos bispos de Alexandria e de Constantinopla como representantes do "padrão da fé cristã" Nissa é considerado um dos maiores exegetas do livro Cântico dos Cânticos e o campeão da interpretação alegórica do mesmo. Tal interpretação pertence à sua obra de maturidade teológica com os principais conceitos que caracterizam seu pensamento ${ }^{7}$.

\section{Contra Eunômio}

Gregório de Nissa se destaca na controvérsia contra o neo-arianista Eunômio, escrevendo três livros para refutá-lo. Esses livros estão estruturados da seguinte forma: 1) Introdução e argumentos históricos; 2) declaração de fé de Eunômio; 3 ) crítica de Eunômio a Basílio. Na primeira parte, Gregório de Nissa esclarece porque defende a Basílio. Na segunda parte, se volta às questões teológicas, citando e criticando com detalhes as declarações de fé elaboradas por Eunômio ${ }^{8}$. Eunômio afirmava que não apenas o "não gerado (o Pai) é a substância de Deus, mas também Deus é a substância não gerada" .

Aqui se encontra o fio condutor da teologia eunomiana, objeto de uma fé metafísica e a premissa maior de todo seu esquema racional. No entanto, é preciso considerar que "o não gerado" do ponto de vista de Eunômio, não se refere a um simples conceito (epinoia), resultado da reflexão humana, pois, se assim o fosse, perderia seu valor absoluto. "O não gerado se impõe ao mesmo tempo no plano do ser e da linguagem" ${ }^{\prime 10}$. O termo diz tudo sobre o ser divino.

\footnotetext{
${ }^{5}$ HEINE, R, 1995:6-7, citado por Papa in Anais do XXVI Simpósio Nacional de História ANPUH • São Paulo, julho 2011, p. 13.

${ }^{6}$ PESTANA, Álvaro, César, Platão e Gregório de Nissa, Letras Clássicas, n. 2, p. 83-114, 1998. Disponível em: <http://www.revistas.fflch.usp.br/letrasclassicas/article/viewFile/604/539>. Acesso em 03 de março de 2014.

${ }^{7}$ GREGORIO DI NISSA. Omelie sul cântico dei cantici. Bologna: EDB, 1995, p. 05.

${ }^{8}$ HALL, G, S. “Contra Eunomium I e II”. In: Gregorio di Nissa. Dizionario. Roma: Città Nuova, 2007, pp. 135-145.

${ }^{9}$ SESBOÜÉ, B. in Pensar a Dios, in Secretariado Trinitário, Salamanca 1997.p. 245.

${ }^{10}$ Idem, 245.
} 
Dessa forma, "o não gerado" é contrário a toda e qualquer possibilidade de ser gerado ou gerar"1.

A consequência disso se reflete no ser do Filho, que é totalmente repelido para fora da esfera divina. A transcendência do "não gerado" é absoluta, não comporta comparação com outro. Para Eunômio, a geração do Filho é inconcebível em Deus. Eunômio recusa também, toda distinção entre geração e devir; tudo o que vem depois do não gerado pertence à ordem do devir e do criado. Eunômio denomina o Filho de rebento, o que se aproxima de criatura, e quando se utiliza o termo luz para o não gerado e para o rebento, o sentido é distinto. Consequentemente, o Espírito é uma criatura do Filho. Assim estamos diante de "um sistema de emanação de tipo neoplatônico, um desenvolvimento da gênese do múltiplo a partir do uno"12.

Do ponto de vista de Sesboüé ${ }^{13}$, o aspecto forte de Eunômio está situado em sua vigorosa intuição do não gerado, enquanto sua fragilidade se insere numa concepção demasiado arbitrária da linguagem; sua destreza está no modo como veste de uma roupagem cristã a uma doutrina não cristã.

Do ponto de vista de Eunômio, Deus é simples e único, portanto, não é possível na mesma substância divina pensar uma dualidade muito menos uma Trindade. O pressuposto da absoluta unidade e simplicidade de Deus responde acima de tudo a uma exigência de ordem teorética: a origem de todo ser e a nossa própria origem devem ser a única à unidade anterior a toda multiplicidade, enquanto deve proceder a multiplicidade dos seres que desse tem origem; o que dá origem deve ser simples privado de toda composição e divisão. O sistema teorético de Eunômio na busca incessante para salvaguardar a simplicidade e unidade da origem de Deus não gerado, pathos que guia a teologia eunomiana e lhe impõe do início ao fim caráter subordina-

${ }^{11}$ EUNOMIO, Apologia PG 30, 837A-868C, trad. italiana, Apologia, Collana di Testi Patristici 192, Città Nuova, Roma 2007. Segundo Filostorgio após a morte de Eunômio o prefeito do pretório Eutropio ordenou que os livros de Eunômio fossem destruídos e que em 398 o imperador Arcádio decretou que todas as suas obras deveriam ser queimadas. Consequentemente temos escassas obras de Eunômio, apenas as seguintes: L 'Apologia, La Professione di Fede apresentada ao imperador Teodósio em 383 e um certo número de fragmentos Dell `Apologia per L 'Apologia citada de Gregório de Nissa. L`Apologia per L 'Apologia é conhecida de forma indireta através das citações de Basílio de Cesaréia que inseriu em seu contra Eunômio por forma direta. (Eunomio apologia Basilio di Cesarea contro eunomio, Roma: Città Nuova, 2007, p.11).

${ }^{12}$ Idem, p. 246.

${ }^{13}$ Para Sesboüé o problema de Eunômio está ligado a compreensão da linguagem. Embora, não se pode desconsiderar o entendimento estreito sobre a questão da Monarquia referente a Deus Pai no século IV. SESBOÜÉ, B, in Pensar a Dios, in Secretariado Trinitário, Salamanca, 1997, p. 247. 
cionista é a expressão de uma ardente paixão pela unidade e simplicidade da existência humana perdida e para sempre desejada, a esperança de encontrá-la em Deus, eternamente simples e único o seu fundamento e sua garantia ${ }^{14}$.

A grande contribuição teológica de Basílio é a "doutrina sobre o Espírito Santo", em contraposição às seitas semi-arianas, que haviam transferido e negado a divindade do Filho e a terceira pessoa da Santíssima Trindade. Basílio oferece uma distinção entre "ousia" e "hypostasis" na Trindade. A "ousia" indica o que é comum e único às três pessoas = natureza e substância. A "hypostasis" constitui a particularidade que constituem cada pessoa da Trindade. Esclarece quem é o Filho, de modo especial em duas ocasiões: em seu ataque contra "Eunomio", e no livro IV sobre o Espírito Santo. Basílio ${ }^{15}$ parte da acusação que lhe faziam porque usava a seguinte doxologia: "Glória ao Pai, com o Filho e com o Espírito Santo" e "Glória ao Pai pelo Filho no Espírito Santo"16.

Em consideração ao fato de Eunômio refutar a crítica de Basílio, a sua simples linguagem tradicional, Gregório de Nissa argumenta em referência aos nomes do Pai do Filho e do Espírito Santo de forma excessiva. Chamando o primeiro ser Supremo e sumamente autêntico, Eunômio nega a supremacia e o senhorio do Filho e do Espírito Santo. Pode-se dizer que, ao negar o ser autêntico do Filho, Eunômio nega a autenticidade da existência do ser. Gregório de Nissa refuta baseado na Sagrada Escritura, que não há fundamentos para subordinar o Espírito Santo ao primeiro e ao segundo Ser. Na teologia capadócia, as pessoas divinas se distinguem por suas características individuais de paternidade, filiação e processão (expiração). A tentativa de Eunômio em fundar a unidade das hipóstasis sobre o vínculo invariável inerente a suas relações é totalmente rejeitada (p. 138).

$\mathrm{Na}$ terceira parte do livro, Gregório de Nissa argumenta contrariando Eunômio em seus métodos lógicos utilizados para criticar Basílio. Gregório de

${ }^{14}$ ZUPI, M. Gregorio di Nissa, Le belle ascese: antologia del "contro Eunômio". Padova: Messaggero, 2001, p. 34.

${ }^{15}$ Basílio se apresenta como aquele que deu grande contribuição a respeito da elaboração das fórmulas trinitárias no que se refere aos conceitos de hipóstasis e substância, como também na reconciliação das terminologias parciais em uso nas Igrejas (comunidades) divididas. Primeiro teve que converter a razão tanto o termo consubstancial de Nicéia como a linguagem das três hipóstasis. Sua lucidez teológica percebia em efeito, a ambiguidade de cada uma dessas terminologias se tomadas isoladamente. Estava consciente de que ao utilizá-las, dever-se-ia considerar que é necessário toma-las de forma complementar (Secretariado Trinitário, 1997, p. 109).

${ }^{16}$ BOBRINSKOY, B. El mistério de la trinidad, in Secretariado Trinitario, Salamanca, 2008, pp. 258-266. 
Nissa afronta questões relativas a ingênito e eterno. Gregório de Nissa parte de fundamento bíblico sobre a revelação de Deus a Abraão dado que Deus se deixa conhecer (Deus Revelatus) progressivamente, porém permanecendo escondido (Deus Absconditus). Nissa parte de uma via apofática onde conhecemos Deus, mas ao mesmo tempo somos conscientes de nossa ignorância. Eunômio é surpreendido pela argumentação de Gregório de Nissa que se distingue de Nicéia e de Ário. Gregório de Nissa distingue entre palavra positiva e negativa em referência a Deus, analisando o uso dos termos privativos e negativos: esta é uma argumentação a qual tende relativizar o termo ingênito que, para Eunômio, era único e fundamental. Gregório de Nissa sustenta que, quando a Escritura trata Deus com termos positivos, trata de suas operações e não de seu Ser; isto será relevante para a teologia grega posterior. Eunômio havia criticado Basílio pelo domínio de noções filosóficas epinoia ao invés de escutar a Escritura.

Gregório de Nissa refuta a ideia de Eunômio, a respeito da identificação entre geração e criação, afirmando que Paternidade e Filiação são eternas e criação é temporal. Fundamentando-se no prólogo joanino, critica a relação intrínseca que Eunômio estabelece entre geração e paixão. Afirma que geração eterna é radicalmente diferente da geração humana. Deus Pai e Filho são co-eternos e possuem a mesma substância e que os termos: Primogênito e Primazia estão relacionados à encarnação. Recorre à distinção entre natureza incriada e natureza criada e afirma que, quando Pedro diz que Deus constituiu Jesus Senhor e Cristo, refere-se não ao Logos eterno, mas àquele que assumiu a forma humana até a humilhação.

Se anteriormente à encarnação já tinha forma de servo, seria inútil Paulo afirmar que tenha assumido na economia. Gregório de Nissa acusa Eunômio de distanciar-se da verdade e de não saber interpretar At 2,36 em que Deus constitui Senhor o Filho encarnado. Outro elemento relevante, que Gregório de Nissa tenta esclarecer, se refere à qual das pessoas é atribuída à salvação. Certamente é impossível afirmar que a natureza divina possa sofrer (morrer). Gregório de Nissa é categórico em afirmar que quem sofre a paixão é o Filho de Deus na humanidade, é o Verbo, através da carne, aquele que cumpre a salvação dos homens.

\section{A teologia apofática no pensamento Nisseno}

A incompreensibilidade do mistério de Deus se faz presente desde o início no ensinamento da Igreja. Para os padres capadócios criadores da linguagem trinitária do mundo grego, Deus é Inefável, a transcendência supera a compre- 
ensão humana ${ }^{17}$. Gregório Nazianzeno ${ }^{18}$ compreende Deus em sua infinita transcendência em sua essência supera sua relação com o mundo e a inteligência humana. Para Nazianzeno, Deus supera a distância no amor no qual a criatura reconhece sua existência e se orienta para seu Criador. Sua teologia é catafática no sentido da observação sobre o cosmo e o estudo da revelação, mas transcende tornando-se apofática. Deus é compreensível nos atributos que caracterizam a obra e no plano da divinização e redenção que concerne ao homem, é mistério absoluto na sua natureza. A relação entre o finito e o infinito é a inefabilidade. Isso refuta a idéia de Eunômio a respeito da possibilidade do ser humano conhecer Deus totalmente. Nazianzeno afirmava que conhecemos a Trindade não por conquista racional, mas por revelação.

Anteriormente a Nazianzeno, no século II, Irineu de Lion ${ }^{19}$, argumenta contra os gnósticos, que o conhecimento de Deus se dá na economia salvífica mediante a Pessoa de Jesus Cristo conforme Mt 11,27 quem testemunha é o próprio Cristo. Do ponto de vista de Benats ${ }^{20}$, para Irineu a intuição do prólogo joanino não se refere apenas à encarnação, mas a toda ação do Filho na história. Durante toda missão Jesus é portador do Pai e toda manifestação do Pai acontece através do Filho. Irineu se refere ao mistério que somente mais tarde será denominado com o termo Pericórese, a recíproca in-existência do Pai no Filho e do Filho no Pai. Isso já se entende no evangelho joanino de que o Filho está no Pai e o Pai está Nele: "Eu e o Pai somos um" (Jo 10, 30) ${ }^{21}$.

Séculos depois, na mesma esteira dos capadócios segue João Damasceno afirmando a mesma compreensão apofática de Deus. Damasceno afirma que nem tudo é exprimível, e nem tudo é incognoscível e nem tudo é cognoscível. O que significa que o Deus revelado é o mesmo que permanece escondido, e o escondido é o revelado. Conhecemos e confessamos que Deus é sem princípio e sem fim, a revelação nos faz conhecer um Deus único em três pessoas ${ }^{22}$. João

\footnotetext{
${ }^{17}$ PRESTIGE, G. Dio nel pensiero dei padri. Bologna: EDB, 1992, p. 247.

${ }^{18}$ TRISOGLIO, F. La salvezza in Gregorio di Nazianzo. Roma: Borla, 2002, p. 25.

${ }^{19}$ IRINEU DE LIÃO. Col. Patrística vol 4. São Paulo: Paulus, 1995, pp. 255-272.

${ }^{20}$ BENATS, B. Il ritmo trinitário dela verità: la teologia di Ireneu di Lione. Roma: Città Nuova, 2006, pp. 192-193.

${ }^{21}$ Para Maximo o Confessor ao interpretar Gregório Nazianzeno mostra que o movimento da natureza divina é aquele que consiste na manifestação do seu existir e do seu subsistir, em certo modo, e esse significa a gnose para aqueles que a recebem. A Trindade é verdadeiramente una, e verdadeiramente trina. (MASSIMO Il CONFESSORE. Ambigua, problemi metafisici e teologici su testi di Gregorio di Nazianzo e Dionigi Areopagita, Trad.. MORESCHINI, C. Milano: Bompiani Il Pensiero occidentale, 2003, p. 577.)

22 DAMASCENO, G. La fede ortodoxa. Roma: Città Nuova, 1998, p.49.
} 
Damasceno parte da experiência batismal e afirma: "Nós acreditamos no Pai, no Filho e no Espírito Santo, nos quais somos batizados"23. João Damasceno é o grande teólogo sistemático do mundo grego no fim da Patrística, que articulou brilhantemente o termo pericórese para exprimir o mistério trinitário de Deus em si mesmo e na sua revelação na economia de salvação.

Significa que a compreensão da transcendência de Deus em seu aspecto incognoscível e inominável está no início da sistematização teológica e em todo seu percurso posterior na história do pensamento teológico centrada em fundamentos veterotestamentário e neotestamentário e nos padres da Igreja acima citados.

Portanto, inicialmente é necessário compreender o fio condutor regente do pensamento de Gregório de Nissa que é a teologia apofática. A palavra apofatismo tem origem no termo grego e deriva do verbo apofasko igual à apófemo, que significa "negar". O livro do Êxodo 33, 20-23, que mostram a transcendência de Deus sobre o homem. Também textos neotestamentário como 1 Tim 6,16; 1 Jo 4,12; Rm 1,20; 2 Cor 12,4, Rm 2,33 são expressões bíblicas que revelam que jamais se viu o rosto de Deus cara a cara (Gn 32,2430; Êx 33,1 Dt 34,10), querem exprimir um encontro pessoal com Deus, porém, envolto em seu mistério. $\mathrm{O}$ apofatismo encontra imensa relevância no Corpus dioniziacum e que influenciou toda teologia mística bizantina. O ponto de partida da teologia negativa de Nissa foi a controvérsia com Eunômio.

A doutrina apofática de Gregório de Nissa é baseada sobre a infinita

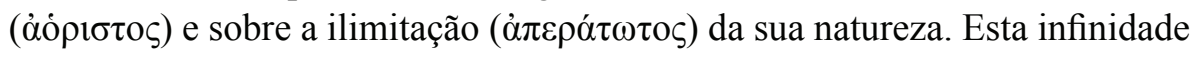
divina compreende, em si, a distância entre a natureza de Deus e a do mundo que é limitado e finito. Gregório de Nissa repele a heresia de Eunômio porque não delimita, não esclarece a natureza de Deus com uma só expressão. A natureza é perfeita ilimitada; a essência divina transcende as coisas sensíveis. Não há forma nem cor, nem circunferência, nem quantidade nem analogia.

A segunda característica da teologia apofática de Gregório de Nissa trata da afirmação da invisibilidade divina. A natureza divina supera toda sensibilidade e transcende a razão humana. Gregório de Nissa nega nossa exatidão sobre o conhecimento de Deus. No entanto, fixa os limites epistemológicos da pesquisa, afirmando que, para a consciência humana é estruturalmente impossível compreender a natureza divina porque é impercorrível a distância entre a criatura finita e a natureza incriada, infinita. Gregório de Nissa retoma

${ }^{23}$ Ibid, p. 61. 
a lição basiliana relativa ao conceito de pensamento humano e segundo o pensamento humano.

Do ponto de vista de Gregório de Nissa, nossa mente colhe qualquer coisa relativamente a Deus. Pode conceber qualquer coisa em relação a Deus, por via negativa ou por via analógica. Aquilo que vem denominado nomes divinos, como geralmente todos os nomes, são invenção do pensamento humano, posterior às coisas e a suas atribuições. As vozes são como sombras das coisas e têm a forma correspondendo aos movimentos daquilo que existe. Também os nomes seguem o movimento de Deus, suas operações, os traços visíveis no criado da potência do Deus invisível.

A teologia de Gregório de Nissa é apofática no sentido de que apófase, nas suas obras, é um instrumento sistemático, como parte de um sistema especulativo por ele construído coerentemente para defender a profissão de fé trinitária. Se examinarmos a teologia apofática em Gregório, veremos duas noções: em primeiro lugar, também, se Gregório recorre habitualmente ao uso do alfa privativo como técnica linguístico-epistemológica ${ }^{24}$, e, certamente prefere uma linguagem negativa quando se refere a Deus por abstração, não desenvolve nem se envolve em um método linguístico formalmente conhecido como apófase, o qual, é no contexto cristão, um contributo de Pseudo-Dionisio Areopagita.

Dessa forma, o método linguístico da apófase não pode ser concebido como um elemento constitutivo do seu sistema apofático. Em segundo lugar, apófase, enquanto instrumento sistemático funciona como princípio teorético compreensivo, que se apoia sobre uma base exegética, mas, que na controvérsia trinitária há um contexto importante para um ulterior desenvolvimento sistemático. O princípio é eficaz no método científico usado por Gregório, conhecido como Akolouthia ou mentalmente Epinoia. Aqui, o princípio é interligado como diretiva epistemológica certa. A incompreensibilidade da natureza de Deus representa um dos princípios dogmáticos que devem ser considerados ao se examinar a doutrina trinitária e a sua estrutura lógica.

A respeito da inominabilidade de Deus, Nissa afirma que esta deriva da simplicidade da natureza divina e os nomes derivam da nossa natureza humana, da nossa razão. A natureza divina está acima de todo nome. $\mathrm{O}$ nome indica aquele em quem nós cremos que opera no âmbito de nossa vida. Völker ${ }^{25}$ observa a exposição de Gregório de Nissa, distinguindo dois

${ }^{24}$ MATEO-SECO, L. F. art. "Teologia apofática". In: Gregorio di Nissa. Dizionario. Città Nuova: Ed. Roma, 2007, pp. 515-520.

${ }^{25}$ VÖLKER, Walte. Gregório di Nissa filosofo e místico, Milano: Vita e Pensiero, 1995, p. 35. 
grupos das qualidades divinas: uma é a qualidade indicativa da majestade divina como os nomes imortais, invisíveis que falam por si mesmos. Outra é a qualidade indicativa em relação, por exemplo, a termos como misericórdia, piedade que são ditos por nós. Nissa nega, contra Eunômio, que o termo ingênito possa exprimir perfeitamente a natureza divina. Distingue três modos expressivos dos nomes divinos: 1) nomes apofáticos; 2) nomes superlativos; 3) nomes simbólicos.

Em relação aos nomes apofáticos, Nissa se refere àquilo que Deus não é, ou seja, o que é, fica obscuro. Os nomes superlativos exprimem que a natureza divina transcende a tudo. Os nomes espirituais ou simbólicos exprimem, também, o sentido da inefabilidade pelo fato de exprimirem não uma palavra sobre Deus, mas sobre uma relação que o humano tenta estabelecer com Deus. Os simbólicos indicam uma consciência parcial sobre Deus. Nissa usa diversos símbolos: a rocha, a nuvem, a luz e o imenso mar quando trata da mística de Moisés nas teofanias ${ }^{26}$ e na reflexão sobre as relações espirituais do esposo do livro do Cântico dos Cânticos. O movimento inacessível versus Deus é unido à estabilidade encontrada em $\mathrm{Cristo}^{27}$.

O sistema argumentativo, organizado segundo o axioma apofático, compreende, seja a essência, isto é a ousia ou o ser como categoria iniludível do momento que Deus, segundo a própria auto-revelação, para Nissa, Deus é Aquele que é $(\operatorname{Ex~} 3,14)$ não é transcendente ao ser, mas acima de todo ser criado, é a suprema realidade do ser. Discutir o ser de Deus significa discutir a realidade e a existência de uma natureza dinâmica existente, (real) não só de qualquer essência abstrata que existiria separadamente referente à própria potência, mediante o exercício do qual não se conhece a existência. É possível verificar isso no discurso contra Eunômio onde a physis divina e dynamis incriada são consideradas dois termos equivalentes relativos à questão que se refere à incompreensibilidade de Deus como um princípio inexprimível (aphraston Logon) o princípio primeiro (arché).

Consequentemente, no sistema apofático de Nissa podem ser encontradas duas principais linhas de argumentação intimamente correlatas, porém distintas: uma que se volta fundamentalmente à physis ou ousia de Deus; a outra que se volta a sua dynamis. Portanto, o sistema apofático de Nissa é constituído por quatro elementos especulativos.

\footnotetext{
${ }^{26}$ GREGORIO DI NISSA. La vita di Mosè Scrittori greci e latini. Milano: Mondadori, 2011.

${ }^{27}$ GREGORIO DI NISSA. Omelie sul Cantico dei Cantici. Bologna: EDB, 1995, pp. 111- 123.
} 
O primeiro elemento é de caráter ontológico. Concerne à divisão entre ser criado e ser incriado a respeito do qual se afirma uma distinção ontológica fundamental entre Deus e a pessoa humana com significativas implicações epistemológicas. Do ponto de vista de Nissa, toda ordem do criado é vinculada à separação, intervalos, limitações e descontinuidade referentes às categorias de tempo e de espaço (diastema); é sempre um estado do devir; no entanto, não existe devir em Deus. Não se aplica a Deus criador do espaço e do tempo. O homem (ktiston e diastêmatikon) ser criado, e Deus (Aktiston e adiastaton) Ser incriado, natureza totalmente espiritual inteligível para a qual não existe limite ${ }^{28}$.

O segundo elemento é diretamente ligado ao primeiro e aponta para o terceiro; é a teoria da linguagem, ou seja, seu argumento linguístico. A linguagem é categoria inevitável para o discurso teológico. A expressão de fé cristã, a profissão de fé trinitária é ligada à linguagem como qualquer comunicação verbal ou escrita. É necessário delimitar, definir a real capacidade de expressão na transmissão de conceitos divinos. O diálogo pertence à ordem do criado convencional e não ôntico; é um produto humano.

O terceiro elemento do sistema apofático de Gregório de Nissa é a distinção entre ousia e energia usada como um argumento epistemológico que oferece a dinâmica fundamental ao sistema em sua totalidade. Portanto, ousia e energia se apresentam epistemologicamente correlatos na sua distinção. Desse ponto de vista, ousia e energia coexistem. A energia de Deus, segundo a qual Ele é conhecido, se manifesta na sua sabedoria, bondade e potência.

O quarto elemento do sistema é um argumento que se refere à bondade de Deus e à potência. Esse argumento se entrelaça com o argumento de caráter ontológico no tratar o conceito de infinito. Esse sistema apofático é essencialmente um sistema teológico por sua motivação: estruturado para estabelecer o ponto de partida fundamental a respeito da compreensão da lógica intrínseca da confissão trinitária de Deus.

Em consonância com o pensamento de Gregório de Nissa Gregório Nazianzeno (389) argumenta que nos é possível compreender a existência de Deus, mas não a sua natureza. Deus permanece incognoscível, divindade incorpórea. Do seu ponto de vista, a Sagrada Escritura mostra as provas da existência da incognoscilidade de Deus. Demonstra ainda a escassez de linguagem que o ser humano tem na explicação das coisas, o que dificulta

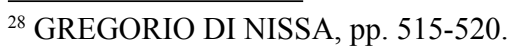


mais ainda explicar racionalmente Deus ${ }^{29}$. Do ponto de vista de V. Lossky, ${ }^{30} \mathrm{o}$ "apofatismo" que está na origem de toda a teologia trinitária, encontra-se especialmente na base da teologia do Espírito Santo, ou seja, da pneumatologia. No caso da Terceira Pessoa da Santíssima Trindade, o ensinamento bíblico já tem o caráter de uma tradição mais secreta, menos revelada, em lugar da manifestação refulgente do Filho, proclamada pela Igreja até os confins do universo $^{16}$. O Espírito Santo permanece não manifestado enquanto pessoa permanece escondida, dissimulando-se no seu próprio aparecimento.

\section{A reflexão trinitária no pensamento de Gregório de Nissa}

A teologia de Nissa é completamente perpassada pela reflexão trinitária que é o verdadeiro fundamento de sua teologia espiritual, e demonstra também estar interligada à cristologia e à pneumatologia com ênfase cristológica. O termo tria aparece oitenta vezes em seus escritos. Do ponto de vista da história do dogma, é extremamente relevante o uso dos termos: prosopa e hipóstasis. É particularmente clara a coincidência entre doutrina trinitária e filiação divina: o Deus cristão é um Deus eternamente generante do próprio Filho, apresentado como Filho do amor do Pai. No entanto, necessita de uma espécie de purificação da compreensão humana sobre filiação.

No pensamento de Gregório de Nissa a ação do Filho é inseparável do agir do Espírito Santo, dando a sua pneumatologia uma ênfase particularmente relevante seja do ponto de vista teológico seja no âmbito histórico. A afirmação de que não se pode pensar o Pai sem o Filho, o mesmo serve em relação ao Espírito Santo, não há como pensar o Filho sem o Espírito Santo. Gregório de Nissa denomina o Espírito Santo de glória e glorificador do Unigênito e convoca tudo à unidade: "O Espírito Santo é a glória que une os homens a Cristo e consequentemente com Deus" ${ }^{31}$.

Portanto, é necessário entender que o primeiro momento de sua teologia é essencialmente gnosiológico, centrado sobre a conexão entre apofatismo e Trindade como exigência imprescindível para uma correta aproximação à teologia do Pai e do Filho e do Espírito Santo. Após essa premissa necessária, Deus é

\footnotetext{
${ }^{29}$ GREGORIO DI NAZIANZO. Tutte le orazioni. Milano: Bompiani, Il Pensiero Occidentale, 2000, pp. 687-689.

${ }^{30}$ V. LOSSKY, La Teologia Mistica delta Chiesa d'Oriente. Bolonha: Il Mulino, 1967, pp. 389-390.

${ }^{31}$ MATEO-SECO, L. “Gloria”. In: Gregorio di Nissa. Dizionario, Roma: Città Nuova, 2007, p. 298.
} 
apresentado no mistério da unidade das três pessoas manifestada no único agir trinitário como reflexo de sua unidade. Isso permite ressaltar a mesma dinâmica imanente de Deus reconhecido não em forma estática, mas, como Deus único e vivo. A consideração das processões e da dinâmica relacional, que caracteriza a vida das Pessoas divinas expressa por Nissa mediante uma analogia psicológica, permite aproximação entre filiação e pneumatologia.

O leitor percebe que a teologia de Nissa é assinalada pela discussão com Eunômio na polêmica sobre o conceito de ingênito aplicado a Deus. Por esse motivo, o elemento essencial de seu pensamento é o apofatismo para refutar a afirmação semiariana que argumenta ser possível compreender a essência divina. Em síntese, Eunômio negava a consubstancialidade das três pessoas, apoiando-se numa teoria neoplatônica e logística dos nomes que o conduzia a professar uma identidade entre o plano gnosiológico e o plano ontológico.

A isso refuta Gregório de Nissa, distinguindo o plano do ser daquele de ser dito. Gregório de Nissa insiste em afirmar que a mente humana pode aproximar-se, jamais abarcar Deus ou esgotar o conhecimento sobre Ele. Argumenta que a Trindade se deixa conhecer na economia de salvação, ou seja, através do agir divino. Segue a via de Basílio o qual afirmava que não se pode conhecer Deus fora da economia de salvação ${ }^{32}$. Clemente de Alexandria reserva a via negativa àqueles que são iniciados no mistério cristão; compreende-o como uma contemplação de Deus. Para Clemente de Alexandria, Jesus Cristo é o pedagogo através do qual conhecemos Deus o Pai ${ }^{33}$.

$\mathrm{O}$ ápice doutrinal entre afirmação e negação, o que significa teologia catafática e teologia apofática se encontra no Concílio de Calcedônia de 451, onde encontramos conceitos, palavras que ao mesmo tempo em que definem, não definem. Destarte, tanto teologia apofática quanto a teologia catafática constituem a linguagem para que o ser humano possa falar do mistério divino e falar com Deus e Dele ao mesmo tempo. Tertuliano ${ }^{34}$ cita os três conceitos: invisível, inefável e incompreensibilidade, ressaltando que nessa dialética reside a verdade e a grandeza do mistério de Deus.

\footnotetext{
${ }^{32}$ LOSSKY V. A immagine e somiglianza di Dio. Bologna: EDB, 1999, pp. 55-7.

${ }^{33}$ CLEMENTE DE ALEJANDRÍA. El pedagogo. Madrid: Ciudad Nueva, 2009, pp. 207-217.

${ }^{34}$ SCORDAMAGLIA, D. Dio Padre nella teologia di Tertulliano. Bologna: EDB, 2011, p. 15.
} 
Gregório Nazianzeno ${ }^{35}$ demonstra que o fazer teológico deve conter dois elementos importantes: a contemplação e a experiência cotidiana. A recordação de Deus permanentemente é o fio condutor para conhecê-lo. Em controvérsia com Eunômio, Gregório Nazianzeno distingue entre o teólogo cristão e aquele dialético representado por Eunômio. Afirma que o apóstolo Paulo distinguia a sabedoria do mistério daquela do mundo. A característica dessa sabedoria é ser escondida (Is 64, 4) ao qual Paulo se refere $(1$ Cor 2, 9). Não se trata de uma refutação ao intelecto, mas, de um redimensionamento das proporções, da superação do intelectualismo platônico e de uma integração da elevação mística platoniana à luz da experiência de Deus. A linguagem greco-helenística tendia a interpretar segundo as próprias categorias os dados narrativos do NT, sem conseguir intuir a radical afirmação da experiência cristã. De outro lado, a experiência cristã experimentava contradições de caráter lógico e cultural. Daí a necessidade em elaborar uma nova metafísica e uma nova hermenêutica capaz de superar a contradição entre o plano da fé e o da expressão lógica.

\section{A unidade das Pessoas}

Gregório de Nissa funda sua reflexão trinitária sobre o dado neotestamentário e litúrgico do batismo. A única vida divina é doada através da graça batismal ${ }^{36}$. As pessoas são conhecidas somente na sua unidade graças ao sentido pessoal que cada uma imprime à única ação divina. Há uma única comunicação e único movimento do Pai pelo Filho no Espírito Santo. Cada pessoa divina é com a outra, nunca separadamente. São unidas sem confundir-se no amor recíproco. O Pai, o Filho e o Espírito Santo são sempre reconhecidos

\footnotetext{
${ }^{35}$ Gregório Nazianzeno argumenta que o fazer teológico deve situar-se ao interno do horizonte da fé ou melhor ainda da vida cristã. Desse modo supera a concepção ariana de uma teologia fundada sobre o racionalismo grego, sobre uma antropologia que vê no pensamento o vértice do homem e que tende a uma contemplação no ética. Orienta verso uma teologia que nasce da profunda interiorização entre consciência mistérica de Deus que a purificação ascética doa e a consciência racional que encontra as categorias para transmiti-la. (PILLONI, F. Teologia come sapienza dela fede: teologia e filosofia nella crisi ariana del IV secolo. Bologna: EDB, 2003, pp. 103-123).

${ }^{36}$ Basílio de Cesareia ao elaborar sua linguagem trinitária tinha presente a fórmula batismal onde demonstra que o batismo estabelece ligação entre glorificação trinitária e fé trinitária. Afirmava que o Espírito Santo é quem realiza a divinização da pessoa no batismo. Assim questionava: "Se o Espírito não merece a nossa adoração, como posso tornar-me divino por meio do batismo"? Se merece a nossa adoração, como pode não ser objeto do nosso culto, como poder não ser Deus? (TENACE, M. Cristiani si diventa, dogma e vita nei primi ter concili. Roma: Lipa, 2013, p. 109.)
} 
na perfeita Trindade, em íntima conexão e união. O que posteriormente é compreendido como pericórese trinitária ad intra.

Já Atanásio ${ }^{37}$ havia várias vezes estabelecido que a mesma relação entre o Espírito Santo e o Filho era a mesma que ocorre eternamente entre o Filho e o Pai. No entanto, frente aos heréticos, Atanásio se limita em afirmar que o Espírito Santo provém de Deus. Para Hilário de Poitiers ${ }^{38}$, a reciprocidade dos dois conceitos Pai e Filho implica necessariamente co-eternidade. Utiliza fundamentos joanino onde Jesus afirma: "Eu e o Pai somos Um”, Hilário diz que "Deve-se crer que o Pai está no Filho e o Filho no Pai" (Jo 10, 30). Percebe-se que a teologia trinitária de Hilário mantém fidelidade a teologia do século IV ${ }^{39}$.

Basílio de Cesaréia $^{40}$ segue a esteira dos padres anteriores que evitam em denominar o Espírito Deus, visto que os problemas com as heresias eram grandes. No entanto, sua linguagem é clara quando afirma que a mesma relação existente entre o Pai e o Filho é a mesma entre o Espírito e o Pai. Em seu Tratado em 375, sua impostação trinitária fundada sobre a unidade de ousia e a Trindade de hipóstases é plenamente elaborada comportando a consubstancialidade e a plena igualdade e divindade do Espírito em respeito ao Pai e ao Filho. Já Gregório Nazianzeno ${ }^{41}$ havia afirmado que o Espírito Santo que procede do Pai enquanto procede não é criatura; enquanto não é gerado não é Filho; enquanto é intermédio entre gerado e ingênito é Deus.

Gregório de Nissa utiliza algumas imagens, sobretudo a do sol para a relação entre a luz não gerada e a luz como raio que coexiste com o sol é manifestação dele o sol. Gregório de Nissa purifica sua imagem, afirmando que não há apenas um raio de sol que sai do sol não gerado, mas que há outro sol que sai do sol não gerado, esplende conjuntamente por geração e que é em tudo co-igual: beleza, potência, esplendor, grandeza e luminosidade. Do ponto de vista de Cirilo de Alexandria ${ }^{42}$ "A inefável glória do Pai brilha sobre o rosto

${ }^{37}$ SIMONETTI, M. La crisi ariana nel IV secolo. Roma: Institutum Patristicum Agustinianum, 1975 , p. 493-495.

${ }^{38}$ HILARIO DE POITIERS, São Paulo: Loyola, 2011, p.99.

${ }^{39}$ Ibid. 137.

${ }^{40}$ Ibid, pp. 493-494.

${ }^{41}$ GREGORIO DI NAZIANZO, Tutte le orazioni, p. 753.

${ }^{42}$ Para Cirilo de Alexandria, somente em Cristo o Verbo, a pessoa humana pode contemplar a glória divina, pode conhecer a Deus. CIRILO DI ALESSANDRIA. Perchè Cristo È uno. Roma: Città Nuova, 1983, p. 92. Já Cirilo de Jerusalém não utilizou o termo homoousios do Concílio de Nicéia 325 em suas catequeses mistagógicas, pelo fato de não está na Bíblia, no entanto, era verdadeiramente ortodoxo na linguagem e confessa o "Cristo verdadeiramente 
de Cristo". Do mesmo modo, vem a terceira Pessoa que não é separada da luz gerada, mas que esplende através dela. Do ponto de vista teológico de Nissa, o Espírito é a pessoa na Trindade que dá acesso em si mesmo à luz que se concebe no Pai e no Filho a todos aqueles que podem participar da vida divina.

Cirilo de Alexandria ao tratar sobre o mistério trinitário utiliza a definição estabelecida em Nicéia 325. Defende a ortodoxia da linguagem da formulação nicena, argumentando que o termo consubstancial é reconhecido e universal. No entanto Cirilo tem consciência da fragilidade da linguagem humana e por isso pede uso com cautela para se falar dos mistérios divinos. Para Cirilo, o ponto de partida é sempre a Trindade econômica, mas o ponto de chegada é a Trindade Imanente. Destarte, elabora um discurso aprofundado sobre Trindade Imanente ${ }^{43}$.

A respeito da unidade das Pessoas, Gregório de Nissa afirma que as três pessoas divinas não se distinguem pela qualidade conexa da essência, mas na recíproca relação ${ }^{44}$. Na mesma linha segue Hilário de Poitiers (367) que afirma a unidade substancial das três divinas Pessoas ${ }^{45}$. Também podemos verificar no pensamento de Gregório de Elvira ${ }^{46}$, referente à unidade de essência das pessoas divinas, quando afirma que o termo homoousios quer significar uma única essência entre Deus Pai e o Filho e que está de acordo com a revelação neotestamentária. Gregório de Nissa afirma que segundo as Escrituras somente podemos professar a fé em um único Deus (Dt 6,4 $)^{47}$.

\section{Considerações finais}

A Tradição Patrística traz em seu cerne a compreensão da teologia não apenas como um saber racional especulativo, mas, sobretudo como sabedoria, experiência mistagógica. Daí a via apofática estar articulada à via catafática no fazer teológico dos padres orientais. Portanto, teologia e poesia se mesclam numa linguagem analógica para denominar o inominável. O incognoscível se

\footnotetext{
Deus e Deus de Deus" e crê na divindade do Espírito Santo. (PETERS, G. I padri della Chiesa, vol. 2 dal concilio di Nicea a Gregório Magno (+604). Roma: Borla, 1991, p. 161).

${ }^{43}$ MONDIN, B. La Trinità mistero d 'amore. Bologna: ESD, 1993, pp.132-135.

${ }^{44}$ COZZI, A. Manuale di dottrina trinitária. Brescia: Queriniana, 2009, p. 376.

${ }^{45}$ BELLOSO. Tratado de Dios uno y trino. Salamanca: Secretariado trinitário, 1993, p. 560.

${ }^{46}$ GREGORIO DE ELVIRA. La fe. Madrid: Ciudad Nueva, 1998, pp. 87-89.

${ }^{47}$ GREGORIO DI NISSA. Opere dogmatiche,trad. MORESCHINI, C. Milano: Bompiani, Il pensiero, occidentale, 2014, p. 1919.
} 
revela e se dá a conhecer se escondendo. Todavia faz-se necessário afirmar que escondimento e revelação não se opõem, mas se interligam constituindo uma realidade de unidade e distinção. Deus se revela ao homem permanecendo o que Ele É. O que os padres querem é salvaguardar a transcendência divina. O Criador supera o criado. A teologia apofática de Gregório de Nissa traz presente a consciência que o ser humano deve ter diante do mistério. Para o cristianismo, o mistério revelado é justamente a manifestação de Deus que se revela no evento Jesus Cristo se relacionando com o humano, onde a Trindade se apresenta como fonte de relações inter-pessoais.

No entanto, falar da transcendência divina numa sociedade que prima pelo palpável, o racional especulativo, exige uma compreensão da linguagem. Diante da realidade atual, uma interrogação nos vem! Como falar de apofatismo? Como dialogar com o homem atual utilizando uma linguagem apofática? O que significa nesse contexto a afirmação de que Deus é revelado e escondido? Daí a consciência de que a linguagem é um produto humano. Afirma que a linguagem vem de Deus, mas não tem sua origem. Considera a linguagem ligada à vocação humana enquanto criatura feita imagem e semelhança de Deus. Um ser pensado para a linguagem. E a própria linguagem pode fazer reconhecer o homem enquanto pessoa habitação do Cristo. Na antiguidade clássica o problema linguístico era tratado seja da filosofia seja da gramática sem que fosse possível traçar uma linha conexa entre os dois âmbitos.

No contexto do século IV Gregório de Nissa soube re-estruturar a linguagem filosófica refutando radicalmente a posição neoplatônica que assegurava ao número uma realidade metafísica. A filosofia da linguagem de Gregório de Nissa se revela de modo particular na discussão sobre a origem do número em âmbito trinitário. Nissa reconduz a gênese do número ao modo físico como evidencia em seu comentário a Gn 1, 7, narrando a divisão das águas acima e abaixo do firmamento. Do ponto de vista de Gregório de Nissa o céu é posto como fronteira separatória da dúplice natureza das águas. Dessa forma, Gregório de Nissa narra todo ato criacional de Deus demonstrando a prioridade ontológica da qual o nível lógico e matemático é somente reflexo. A teoria da consciência de Gregório de Nissa é extremamente realista, evidenciando que a numeração não reconduz a esfera do divino, a criação mesma ligada ao dinamismo e ao modo de ser limitado da esfera criatural. Gregório de Nissa refuta a teoria de Eunômio que visualizava ao próprio interno não somente uma progressiva expansão das temáticas, mas, também um progressivo aprofundamento metodológico. 
O apofatismo de Nissa está sobretudo a serviço do dogma trinitário pelo fato de que a Trindade se conhece a partir do agir divino, e a única vida divina é doada ao ser humano através da graça batismal. Toda sua reflexão trinitária se fundamenta sobre o dado neotestamentário e litúrgico do batismo. Em sua discussão com Eunômio, Gregório de Nissa re-estrutura a linguagem filosófica aplicada ao desenvolvimento do dogma da Trindade, distinguindo imanência e economia ao mesmo tempo que as interliga, utilizando para sua argumentação o termo filiação divina. A distinção entre criado e incriado permite a Gregório de Nissa a base correta da formulação trinitária: o Filho une eternidade e história. Somente é possível entender a linguagem apofática de Gregório de Nissa se a compreende no interior da teologia trinitária, percebendo que sua teologia é apofática no sentido de que apófase, nas suas obras, é um instrumento sistemático, como parte de um sistema especulativo por ele construído coerentemente para defender a profissão de fé trinitária.

Gregório de Nissa está no âmbito da sistematização e defesa de uma linguagem que expresse o mistério trinitário no diálogo entre a linguagem da revelação e a filosofia. A criação e adequação de conceitos se inserem no cerne das necessidades e exigências de seu tempo. Corresponde a um desafio a fé e a resposta na perspectiva da fé. Cada contexto é prenhe de suas exigências, desafios e perspectivas. Quando se trata da fé de uma linguagem sobre Deus, faz se necessário a criatividade, a inculturação, sem, contudo, perder de vista aquilo que constitui a essência do mistério, isto é: Imanência e Economia não se opõem, porém não se confundem. Daí a importância relevante de que toda e qualquer linguagem sobre a Deus será sempre analógica.

A teologia de Gregório de Nissa tem dois aspectos importantes: o aprofundamento do mistério que não priva o mesmo da possibilidade de comunicação e não negue ao homem a possibilidade de ascender-se mediante a experiência mística e a contemplação. No entanto, é necessário considerar que no pensamento de Nissa tendo-se em conta a teologia apofática, o conhecimento da natureza divina supera a inteligência humana. Já Eunômio se coloca em âmbito geral de um neoplatonismo alexandrino e organiza os principais textos do arianismo e do anomeismo de Aécio em um sistema orgânico. Tudo isso dá base para que na atualidade se possa perceber que a linguagem sistemática da fé se insere dentro da cultura para com essa dialogar.

Destarte, compreender o mistério de Deus que se revela, no pensamento de Gregório de Nissa inclui adesão à teoria da consciência de Deus que é uma teoria da experiência do amor entre o amado e a amada. $\mathrm{O}$ conhecimento de 
Deus significa fazer experiência do seu amor. É a dinâmica mesma do conhecer e do ser um continuo transpassar recíproco de identidade e diferença. Silêncio e palavra, mística e filosofia. É uma via mística o contato místico com Deus, exige novamente uma compreensão filosófica de Deus e o pensar novamente exige um encontro. Conhecer Deus é um processo mistagógico, já que Ele é revelado e escondido. É uma infinita dinâmica de revelação e escondimento ${ }^{48}$.

\section{Referências bibliográficas}

CLEMENTE DE ALEJANDRÍA. El pedagogo. Madrid: Ciudad Nueva, 2009. (Basilio di Cesarea, Contro eunomio, Roma: Città Nuova, 2007, p. 11)

BELLOSO. Tratado de Dios uno y trino. Salamanca: Secretariado trinitário, 1993.

BENEDITO XVI. Los padres de la Iglesia, De Clemente de Roma a san Agustin. Madrid: Ciudad Nueva, 2008.

BENATS, B. Il ritmo trinitário dela verità: la teologia di Ireneu di Lione. Roma: Città Nuova, 2006.

BOBRINSKOY, B. El mistério de la trinidad. Salamanca: Secretariado Trinitario, 2008.

CIRILO DI ALESSANDRIA. Perchè Cristo E'uno. Roma: Città Nuova, 1983, p. 92.

COZZI, A. Manuale di dottrina trinitária. Brescia: Queriniana, 2009, p. 376.

DAMASCENO, G. La fede ortodoxa. Roma: Città Nuova, 1998.

EUNOMIO. Apologia PG 30, 837A-868C, trad. italiana, Apologia, Collana di Testi Patristici 192, Roma: Città Nuova, 2007.

GREGORIO DI NAZIANZO. Tutte le orazioni. Milano: Bompiani, Il Pensiero Occidentale, 2000.

GREGÓRIO DE NISSA. Omelie sul Cantico dei Cantici. Bologna: EDB, Bologna, 1995.

${ }^{48}$ ZUPI, M., GREGORIO DI NISSA. Le belle ascese: antologia del "contro Eunômio". Padova: Messaggero, 2001, p. 315. 
GREGORIO DI NISSA. La vita di Mosè Scrittori greci e latini. Milano: Mondadori, 2011.

GREGORIO DI NISSA. Opere dogmatiche, trad. Moreschini, C. Milano: Bompiani, Il pensiero, occidentale, 2014, p. 1919.

GREGORIO DE ELVIRA. La fe. Madrid: Ciudad Nueva, 1998.

HEINE, R, 1995:6-7, citado por Papa in Anais do XXVI Simpósio Nacional de História - ANPUH, São Paulo, julho 2011, p. 13.

HILARIO DE POITIERS. São Paulo: Loyola, 2011.

IRINEU DE LIÃO. Col. Patrística vol. 4. São Paulo: Paulus, 1995.

LOSSKY V., A immagine e somiglianza di Dio, EDB, Bologna, 1999.

MASSIMO Il CONFESSORE. Ambigua, problemi metafisici e teologici su testi di Gregorio di Nazianzo e Dionigi Areopagita, Trad. MORESCHINI, C. Milano: Bompiani Il Pensiero occidentale, 2003.

MONDIN, B. La Trinità mistero d àmore. Bologna: ESD,1993.

MATEO - SECO L.F.-MASPERO G., ed., Gregorio di Nissa. Dizionario, Roma, Città Nuova, 2007.

MORESCHINI. I padri cappadoci, storia, letteratuta, teologia. Roma: Città Nuova, 2008, p. 09.

PAPA, Helena, Amália. O ideal político-religioso niceno na defesa da divindade de Jesus Cristo: considerações iniciais sobre a visão de Gregório de Nissa (séc. IV d.C.) in Anais do XXVI Simpósio Nacional de História - ANPUH • São Paulo, julho 2011, p. 12.

PETERS, G. I padri della Chiesa, vol. 2 dal concilio di Nicea a Gregório Magno (+604). Roma: Borla, 1991, p. 161.

PESTANA, Álvaro, César, Platão e Gregório de Nissa. Letras Clássicas, n. 2, p. 83-114, 1998. Disponível em: <http://www.revistas.fflch.usp.br/ letrasclassicas/article/viewFile/604/539>. Acesso em 03 de março de 2014.

PILLONI, F. Teologia come sapienza dela fede: teologia e filosofia nella crisi ariana del IV secolo. Bologna: EDB, 2003.

PRESTIGE, G. Dio nel pensiero dei padri. Bologna: EDB, 1992. 
SCORDAMAGLIA, D. Dio Padre nella teologia di Tertulliano. Bologna: EDB, 2011.

SESBOÜÉ, B. in Pensar a Dios, Salamanca in Secretariado Trinitário, 1997.

SIMONETTI, M. La crisi ariana nel IV secolo. Roma: Institutum Patristicum Agustinianum, 1975.

TENACE, M. Cristiani si diventa, dogma e vita nei primi ter concili. Roma: Lipa, 2013.

TRISOGLIO, F. La salvezza in Gregorio di Nazianzo. Roma: Borla, 2002, p. 25.

VÖLKER, W. Gregório di Nissa filosofo e místico. Milano: Vita e Pensiero, 1995.

ZUPI, M., GREGORIO DI NISSA. Le belle ascese: antologia del "contro Eunômio". Padova: Messaggero, 2001.

Maria Freire da Silva

Doutora em Teologia Dogmática pela Pontificia Università Gregoriana (Roma) Professora de teologia na PUC-SP São Paulo / SP - Brasil E-mail: mfreire.silva@pucsp.br

Recebido em: 19/02/15

Aprovado em: 15/06/15 